\title{
Asymmetric conjugate additions of dialkylzinc reagents to enones promoted by new purely atropisomeric phosphoramidite ligands
}

\author{
Patrizia Scafato, Stefano Superchi, and Carlo Rosini* \\ Dipartimento di Chimica, Università della Basilicata, via Nazario Sauro 85, 85100 Potenza, \\ Italy \\ E-mail: carlo.rosini@unibas.it
}

\section{Dedicated to Professor Arlette Solladié-Cavallo on the occasion of her significant anniversary}

\begin{abstract}
Enantiopure 1,1'-binaphthylazepine was employed in the preparation of two new phosphoramidites by reaction of the corresponding dichlorophosphoramidite with $(R)$ - or $(S)$ BINOL. In such compounds the chirality of both diol and amine moieties is only due to atropisomerism. Their catalytic efficiency was tested in the enantioselective copper-catalyzed conjugate addition of dialkylzinc reagents to acyclic, cyclic and macrocyclic $\alpha, \beta$-unsaturated ketones. Interestingly, the diastereoisomeric ligands provided the same enantioselectivity in the addition to chalcone, but worked differently with cyclic and macrocyclic enones. The best result, as far as enantiomeric excess is concerned, was observed in the conjugate addition of $\mathrm{Me}_{2} \mathrm{Zn}$ to 2-cyclopentadecenone, affording the valuable fragrance (-) muscone in $84 \%$ ee.
\end{abstract}

Keywords: Phosphoramidite ligands, atropisomeric chirality, asymmetric conjugate addition, binaphthylazepine, muscone

\section{Introduction}

Enantioselective conjugate addition of dialkylzinc reagents to $\alpha, \beta$-unsaturated enones is an important synthetic method for the stereoselective formation of carbon-carbon bonds and nowadays represents a well-developed research area. ${ }^{1}$ It is also noteworthy that, by this reaction, it is possible to set up very efficient preparations of several, useful biologically active compounds. ${ }^{2}$ The main reason of this success resides in the development of some enantiopure trivalent phosphorus compounds (mainly phosphites and phosphoramidites) which, acting as ligands for copper (I) or (II) ions, give rise to catalytically active species capable of directing stereoselectively the addition of the organometallic reagents to the $\alpha, \beta$-unsaturated compounds. 
On the other hand dialkylzinc reagents tolerate many functional groups and can even be used to introduce new functionalities. Taking into account that small changes in the steric and/or electronic properties of the chiral ligand can often lead to a remarkable variation of the catalytic efficiency, also strongly dependent on the structure of the substrate, many efforts have been made in designing new ligands to improve reactivity and enantioselectivity.

As far as the phosphoramidite family, introduced by Alexakis ${ }^{3}$ and developed by Feringa, ${ }^{4}$ is concerned, they can derive from optically pure 2,2'-dihydroxy-1,1'-binaphthyl (BINOL) and an achiral or centrally-chiral amine ${ }^{4 \mathrm{c}}$ or are biphenol-based ligands ${ }^{5}$ (Figure 1).
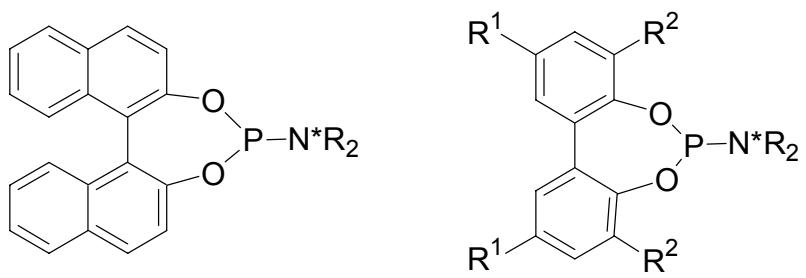

\section{Figure 1}

However, in spite of the myriad of such ligands reported in the literature, ${ }^{1,4,5}$ the preparation and application of phosphoramidites derived from a diol and an amine showing both only atropisomeric chirality, is lacking. Taking into account that many chiral 1,1'-binaphthylazepinebased compounds have been successfully employed in several catalytic asymmetric processes, both as organocatalyst ${ }^{6}$ and ligands in metal complex-catalysed reactions, ${ }^{7}$ we decided to prepare and test the ligands $(\boldsymbol{R}, \boldsymbol{S})-\mathbf{1}$ and $(\boldsymbol{S}, \boldsymbol{S})-\mathbf{2}$ (Scheme 2) in which a BINOL-based phosphorous moiety is linked to an axially chiral $(S)-1,1$ '-binaphthylazepine.

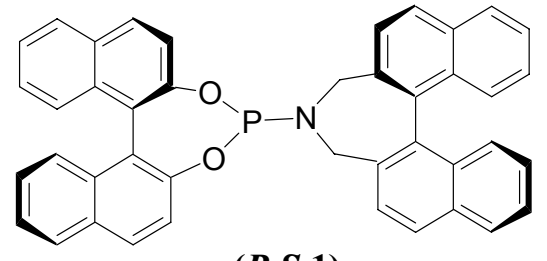

$(R, S-1)$

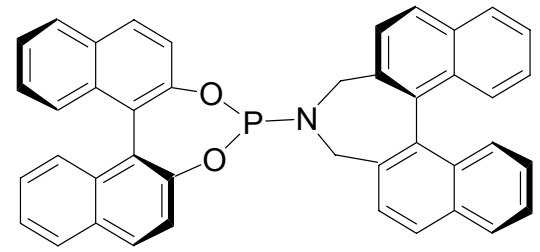

$(S, S-2)$

Figure 2. Structure of new phosphoramidites.

\section{Results and Discussion}

Preparation of the ligands. In Scheme 1 is summarized the synthetic procedure for diastereoisomeric phosphoramidites $(R, S)-1$ and $(S, S)-2$ obtained by reaction of $(R)$ - or $(S)$ BINOL, respectively, with the dichlorophosphoramidite of amine $3{ }^{2 \mathrm{~h}}$ First, starting from $(S)$ - 
BINOL, we prepared (S)-2,2'-bis(bromomethyl)-1,1'-binaphthalene 4 according to a reported procedure. ${ }^{8}$ The latter was then transformed in the corresponding hydroxylamine 5 in $65 \%$ yield, by treatment with hydroxylamine hydrochloride and triethylamine and refluxing for $15 \mathrm{~h}$. The following reduction of compound $\mathbf{5}$ with zinc and catalytic amount of indium in boiling ethanol ${ }^{9}$ afforded binaphthylazepine 3 in 97\% yield, after purification by column chromatography. Finally, the simple addition of $(R)$ - or $(S)$-BINOL, respectively, to a solution of dichlorophosphoramidite of amine 3 in THF, prepared in situ treating 3 with $\mathrm{PCl}_{3}$ and $\mathrm{NEt}_{3}$, afforded ligands $(\boldsymbol{R}, \boldsymbol{S})-\mathbf{1}$ and $(\boldsymbol{S}, \boldsymbol{S})-\mathbf{2}$ in $40 \%$ yield, after purification by flash chromatography on neutral aluminium oxide.<smiles>Oc1ccc2ccccc2c1-c1c(O)ccc2ccccc12</smiles>

$\begin{array}{ll}(\boldsymbol{R}, \boldsymbol{S})-\mathbf{1} & \stackrel{(R)-\mathrm{BINOL}}{\longleftarrow} \\ (\boldsymbol{S}, \boldsymbol{S})-2 & \stackrel{(S)-\mathrm{BINOL}}{\longleftarrow}\end{array}$<smiles>BrCc1ccc2ccccc2c1-c1c(CBr)ccc2ccccc12</smiles>
4

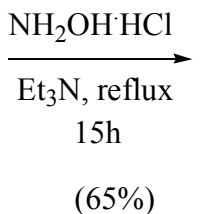

$(65 \%)$

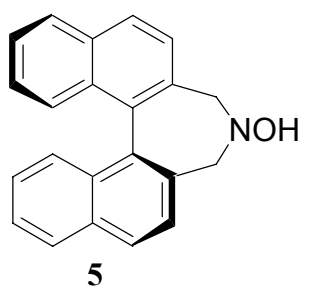

(97\%) $\begin{aligned} & \mathrm{In}, \mathrm{Zn} \\ & \text { EtOH, } \mathrm{NH}_{4} \mathrm{Cl} \\ & \text { reflux, 27h }\end{aligned}$

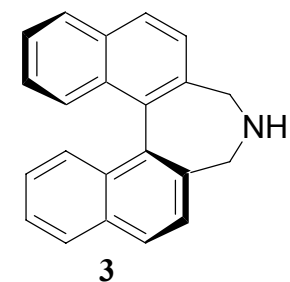

Scheme 1. Synthesis of phosphoramidites $(\boldsymbol{R}, \boldsymbol{S})-\mathbf{1}$ and $(\boldsymbol{S}, \boldsymbol{S})-\mathbf{2}$.

Asymmetric conjugate additions to trans-chalcones. First of all, phosphoramidites $(\boldsymbol{R}, \boldsymbol{S}) \mathbf{- 1}$ and $(S, S)-2$ were employed as ligands in the copper-catalysed conjugate addition of diethylzinc to acyclic enones. In a typical procedure the catalytic system was generated in situ by adding the ligand to a suspension of $\mathrm{Cu}(\mathrm{OTf})_{2}$ in toluene and stirring for $1 \mathrm{~h}$ at room temperature. The resulting solution was cooled to the reported temperature (see Table 1) and enone and $\mathrm{Et}_{2} \mathrm{Zn}$ were added in sequence. The results obtained for the addition of $\mathrm{Et}_{2} \mathrm{Zn}$ to acyclic enones are summarized in Table 1. The effect of temperature, amount of catalyst and copper:ligand ratio was investigated using trans-chalcone and $(\boldsymbol{R}, \boldsymbol{S})-\mathbf{1}$ as ligand (entries 1-5): the best results were obtained using $3 \mathrm{~mol} \%$ of $\mathrm{Cu}$ salt and a copper:ligand ratio $1: 2$ at $-40{ }^{\circ} \mathrm{C}$ affording the product, after purification, in $95 \%$ yield and $72 \%$ e.e. (entry 2). On lowering the temperature, a remarkable loss of catalytic activity and stereoselection was achieved. Less satisfactory results in terms of both yield and e.e. of the product were also obtained on varying copper to ligand ratio 
(entry 4) and lowering the amount of catalyst (entry 5). In order to estimate the role played by the binaphthylazepine moiety on the enantioselectivity, we performed the addition of $\mathrm{Et}_{2} \mathrm{Zn}$ to chalcone in the presence of $(\boldsymbol{S}, \boldsymbol{S})$-2 obtaining the product with opposite absolute configuration and the same enantiomeric excess (entry 6). This result clearly shows that, at least in this case, the chirality of the binaphthylazepine moiety does not affect the asymmetric induction of the reaction, which only depends on the chirality of the binaphthyl moiety deriving from BINOL.

Two $p$-substituted chalcones were also used as substrates in the asymmetric addition of $\mathrm{Et}_{2} \mathrm{Zn}$ mediated by phosphoramidite $(\boldsymbol{R}, \boldsymbol{S})-\mathbf{1}$ : with $p$-Cl substituted chalcone (entry 7 ) results analogous to the unsubstituted derivative were obtained, while the presence of an electron-donating group, such as -OMe group, gave a lowering of reactivity and asymmetric induction (entry 8).

Table 1. Asymmetric conjugate addition of $\mathrm{Et}_{2} \mathrm{Zn}$ to trans-chalcones
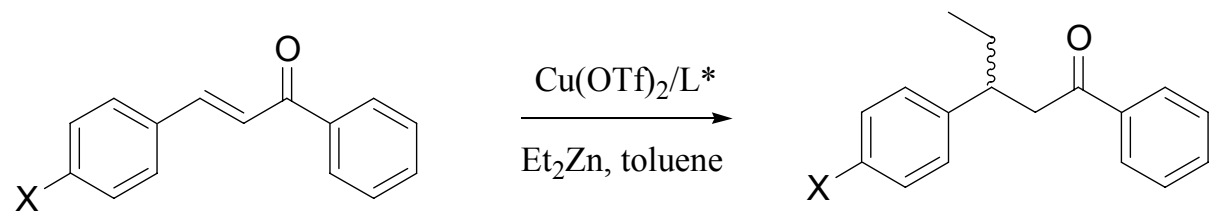

\begin{tabular}{ccccccccc}
\hline Entry & $\mathrm{X}$ & $\mathrm{L}^{*}$ & $\begin{array}{c}\mathrm{Cu}(\mathrm{OTf})_{2} \\
(\mathrm{~mol} \%)\end{array}$ & $\mathrm{Cu}(\mathrm{OTf})_{2} / \mathrm{L}^{*}$ & Time$(\mathrm{h})$ & $\begin{array}{c}\mathrm{T}\left({ }^{\circ} \mathrm{C}\right) \\
\text { Yield } \\
(\%)^{\mathrm{a}}\end{array}$ & $\begin{array}{c}\text { ee}(\%)^{\mathrm{b}} \\
(\mathrm{a} . \mathrm{c} .)^{\mathrm{c}}\end{array}$ \\
\hline 1 & $\mathrm{H}$ & $(\boldsymbol{R}, \boldsymbol{S})-\mathbf{1}$ & 3 & $1: 2$ & 1 & -20 & 88 & $70(\mathrm{~S})$ \\
2 & $\mathrm{H}$ & $(\boldsymbol{R}, \boldsymbol{S})-\mathbf{1}$ & 3 & $1: 2$ & 1 & -40 & 95 & $72(\mathrm{~S})$ \\
3 & $\mathrm{H}$ & $(\boldsymbol{R}, \boldsymbol{S})-\mathbf{1}$ & 3 & $1: 2$ & 7 & -65 & $8^{\mathrm{d}}$ & $40(\mathrm{~S})$ \\
4 & $\mathrm{H}$ & $(\boldsymbol{R}, \boldsymbol{S})-\mathbf{1}$ & 3 & $1: 1.2$ & 1 & -40 & 60 & $58(\mathrm{~S})$ \\
5 & $\mathrm{H}$ & $(\boldsymbol{R}, \boldsymbol{S})-\mathbf{1}$ & 1 & $1: 2$ & 2 & -40 & 60 & $50(\mathrm{~S})$ \\
6 & $\mathrm{H}$ & $(\boldsymbol{S}, \boldsymbol{S})-\mathbf{2}$ & 3 & $1: 2$ & 1 & -40 & 97 & $72(\mathrm{R})$ \\
7 & $\mathrm{Cl}$ & $(\boldsymbol{R}, \boldsymbol{S})-\mathbf{1}$ & 3 & $1: 2$ & 1 & -40 & 87 & $70-$ \\
8 & $\mathrm{OMe}$ & $(\boldsymbol{R}, \boldsymbol{S})-\mathbf{1}$ & 3 & $1: 2$ & 4 & -40 & 63 & $40-$ \\
\hline
\end{tabular}

${ }^{a}$ Isolated product. ${ }^{b}$ Determined by HPLC analyses on Chiralcel OJ. ${ }^{c}$ Determined by the sign of optical rotation. ${ }^{\mathrm{d}}$ Chalcone $(7 \%)$ and a mixture of by-products $(80 \%)$ were recovered.

Asymmetric conjugate additions to 2-cyclohexenone. It is well known that the efficiency of phosphorous ligands strongly depends on the nature of the substrate. ${ }^{1 \mathrm{a}, 2 \mathrm{a}}$ In fact, only a few ligands show good enantioselectivity with both acyclic and cyclic enones or with differently sized cyclic enones. ${ }^{1 \mathrm{c}, 10}$ Therefore, we were interested in checking the catalytic efficiency of ligands $(R, S)-1$ and $(S, S)-2$ in the asymmetric conjugate addition of dialkylzinc reagents to different cyclic or macrocyclic enones.

Herein we report on the results obtained in the conjugate addition of diethylzinc to 2cyclohexenone, taken as a model of cyclic enone, mediated by phosphoramidites $(\boldsymbol{R}, \boldsymbol{S}) \mathbf{- 1}$ and $(\boldsymbol{S}, \boldsymbol{S})-2$ (Table 2). (R)-3-ethylcyclohexanone was obtained, after purification, in $70 \%$ yield and 
moderate e.e. $(60 \%)$, when the catalyst was generated from $(\boldsymbol{R}, \boldsymbol{S})-\mathbf{1}$, while, under the same experimental conditions, ligand $(\boldsymbol{S}, \boldsymbol{S})$-2 afforded the product in the same yield but with lower e.e. $(40 \%)$ and opposite configuration. Comparing these results with those obtained in the addition to chalcone we observed a lowering of both catalytic activity and enantioselectivity with 2cyclohexenone, but, very interestingly, in this case the degree of stereocontrol of the two diastereoisomeric ligands was quite different. In fact, although the absolute configuration of the product still depended on the configuration of the BINOL fragment of phosphoramidites, the chirality of the binaphthylazepine moiety provided a relevant contribute to the enantioselectivity of the reaction. Moreover, the e.e.'s values indicate that, with respect to ligands $(\boldsymbol{R}, \boldsymbol{S})-\mathbf{1}$ and $(S, S)-2$, the matched couple was the one possessing the $(R)$-configured BINOL moiety linked to the $(S)$-binaphthylazepine.

Table 2. Asymmetric conjugate addition of $\mathrm{Et}_{2} \mathrm{Zn}$ to 2-cyclohexenone

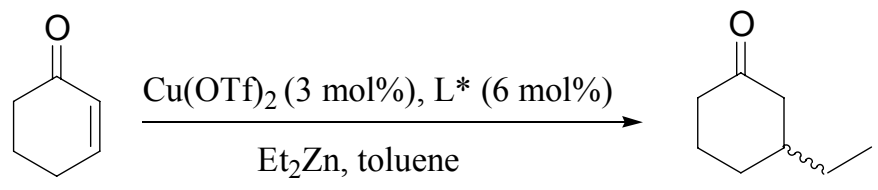

\begin{tabular}{cccccc}
\hline Entry & $\mathrm{L}^{*}$ & $\mathrm{~T}\left({ }^{\circ} \mathrm{C}\right)$ & Time $(\mathrm{h})$ & ${\text { Yield }(\%)^{\mathrm{a}}}$ & $\mathrm{Ee}^{\mathrm{b}}(\mathrm{a} . \mathrm{c} .)^{\mathrm{c}}$ \\
\hline 1 & $(\boldsymbol{R}, \boldsymbol{S})-\mathbf{1}$ & -30 & 2 & 70 & $60(\mathrm{R})$ \\
2 & $(\boldsymbol{S}, \boldsymbol{S})-\mathbf{2}$ & -30 & 2 & 70 & $40(\mathrm{~S})$ \\
\hline
\end{tabular}

${ }^{\mathrm{a}}$ Isolated product. ${ }^{\mathrm{b}}$ Determined by HPLC analyses on Chiralcel OD on the corresponding dioxolane obtained with $(R, R)$-1,2-diphenylethane-1,2-diol. ${ }^{\mathrm{c}}$ Determined by the sign of optical rotation.

Asymmetric conjugate additions to $E$-2-cyclopentadecenone: synthesis of (-)-muscone. On the basis of the results obtained for chalcone and 2-cyclohexenone, for comparative purposes, we became interested in testing the efficiency of these ligands in the addition of dialkylzinc reagents to a macrocyclic enone, such as E-2-cyclopentadecenone. Macrocyclic $\alpha, \beta$-unsaturated ketones are considered a particular case because the size of the ring allows for s-cis and s-trans conformational interconversion and so they generally behave as acyclic enones rather than 2cyclohexenone, which is a representative example of a conformationally fixed s-trans enone. ${ }^{\text {a }}$ Moreover, E-2-cyclopentadecenone is also the precursor of the well known valuable fragrance $(R)$-(-)-muscone, ${ }^{11}$ obtainable by asymmetric addition of $\mathrm{Me}_{2} \mathrm{Zn}$ to this macrocyclic $\alpha, \beta$ unsaturated ketone. ${ }^{5 \mathrm{c}, 6,12}$

In Table 3 are listed the results obtained in the conjugate addition of diethylzinc and dimethylzinc to 2-cyclopentadecenone mediated by phosphoramidites $(\boldsymbol{R}, \boldsymbol{S})-\mathbf{1}$ and $(\boldsymbol{S}, \boldsymbol{S})-\mathbf{2}$. The additions of diethylzinc were performed in the same experimental conditions used for the other enones providing, with $(\boldsymbol{R}, \boldsymbol{S})-\mathbf{1},(R)$-3-ethylcyclopentadecanone in $74 \%$ e.e., a value comparable with that observed in the addition to chalcone. (Table 3 , entry 1 ). When the reaction was 
performed in the presence of $(\boldsymbol{S}, \boldsymbol{S})-\mathbf{2}$, the enantioselection was lower (entry 2) pointing out a real contribute of the chirality of the binaphthylazepine moiety to the enantioselectivity of the reaction, as previously observed in the ethylation of cyclohexenone.

The conjugate additions of dimethylzinc, due to the lower reactivity of this organometallic reagent, were carried out under different experimental conditions, i.e. higher temperature and longer reaction time, in order to obtain complete conversion. Much to our delight, an increase of e.e. was observed in the methylation of 2-cyclopentadecenone promoted by ligand $(\boldsymbol{R}, \boldsymbol{S})-\mathbf{1}$, affording (R)-(-)-muscone in good yield (72\%) and $82 \%$ e.e. (entry 3). This result is very interesting taking into account that dimethylzinc often provides lower enantioselection and chemical yield and affords, in addition to the alkylation products, a consistent amount of byproducts deriving from the conjugate addition of the resulting zinc enolate to the starting enone. ${ }^{2 a}$ Also in this case, a decrease of enantioselectivity was observed when the addition of $\mathrm{Me}_{2} \mathrm{Zn}$ was mediated by $(\boldsymbol{S}, \boldsymbol{S})-\mathbf{2}$ (entry 4$)$.

Table 3. Asymmetric conjugate addition of $\mathrm{R}_{2} \mathrm{Zn}$ to $E$-2-cyclopentadecenone

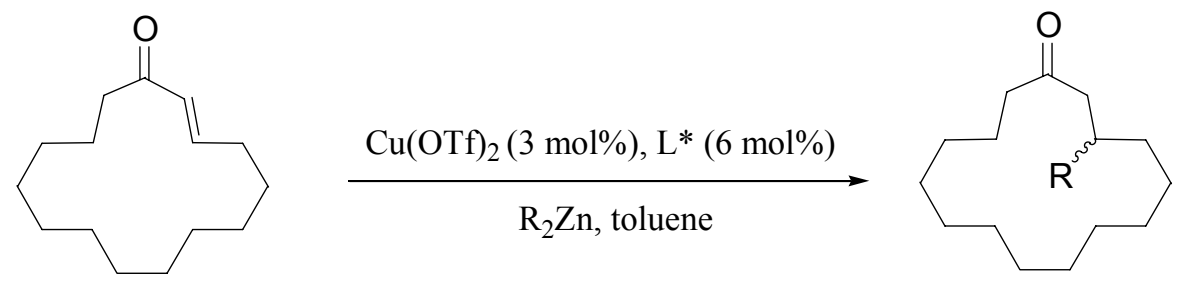

\begin{tabular}{ccccccc}
\hline Entry & $\mathrm{R}$ & $\mathrm{L}^{*}$ & $\mathrm{~T}\left({ }^{\circ} \mathrm{C}\right)$ & $\mathrm{t}(\mathrm{h})$ & ${\text { Yield }(\%)^{\mathrm{a}}}$ & $\mathrm{Ee}^{\mathrm{b}}(\mathrm{a} . \mathrm{c} .)^{\mathrm{c}}$ \\
\hline 1 & $\mathrm{Et}$ & $(\boldsymbol{R}, \boldsymbol{S})-\mathbf{1}$ & -30 & 1 & 75 & $74(\mathrm{R})$ \\
2 & $\mathrm{Et}$ & $(\boldsymbol{S}, \boldsymbol{S})-\mathbf{2}$ & -30 & 1 & 78 & $52(\mathrm{~S})$ \\
3 & $\mathrm{Me}$ & $(\boldsymbol{R}, \boldsymbol{S})-\mathbf{1}$ & 0 & 3 & 72 & $82(\mathrm{R})$ \\
4 & $\mathrm{Me}$ & $(\boldsymbol{S}, \boldsymbol{S})-\mathbf{2}$ & 0 & 3 & 61 & $68(\mathrm{~S})$ \\
\hline
\end{tabular}

${ }^{a}$ Isolated product. ${ }^{b}$ Determined by chiral GC analysis with Hydrodex- $\beta-3 P$ column. ${ }^{c}$ Determined by the sign of optical rotation.

\section{Conclusions}

This work describes the preparation and application in catalytic asymmetric conjugate addition of two new phosphoramidite ligands deriving from $(R)$ - or (S)-BINOL and a chiral binaphthylazepine. Unlike the myriad of phosphoramidites reported in literature, deriving from enantiopure BINOL and an achiral or centrally-chiral amine, in such compounds also the chirality of the amine moiety is due only to atropisomerism. Their catalytic efficiency has been tested in the copper-catalysed asymmetric 1,4-addition of dialkylzinc reagents to rigid and 
flexible enones affording the products with moderate/good e.e. (up to 82\%). The obtained results allow us to reach to the following conclusions: first of all, the contribute of the binaphthylazepine moiety to the stereoselectivity of the reaction strongly depends on the nature of substrate. In fact, no difference of stereocontrol between the two diastereoisomers has been observed in the addition of diethylzinc to chalcone, while different values of ee's have been obtained in the additions to differently sized cyclic enones. However, in any case the sense of asymmetric induction is still governed by the configuration of the BINOL moiety of ligands. Second, interestingly, both ligands give higher e.e.'s values in the additions to macrocyclic enone with the less reactive dimethylzinc than with diethylzinc. In this way, a protocol has been set up by which the natural antipode of muscone can be prepared in good yield and high enantiomeric excess.

\section{Experimental Section}

General Procedures. ${ }^{1} \mathrm{H}-\mathrm{NMR}$ and ${ }^{13} \mathrm{C}-\mathrm{NMR}$ spectra were recorded in $\mathrm{CDCl}_{3}$ on a Varian AS500 $500 \mathrm{MHz}$ spectrometer using TMS as the internal standard. Optical rotations were measured with a JASCO DIP-370 digital polarimeter. Melting points were taken using a Kofler Reichert-Jung Thermovar apparatus and are uncorrected. GC-MS analyses were performed on a Hewlett Packard 6890 chromatograph equipped with a HP-5973 mass detector. Chromatography separations were carried out on suitable dimension columns using Macherey-Nagel silica gel 60 (70-230 mesh) or neutral aluminium oxide. Analytical thin-layer chromatography (TLC) was performed on Macherey-Nagel aluminium sheets precoated with silica gel $(0.25 \mathrm{~mm})$.

Enantiomeric excesses of 3-ethyl and 3-methylcyclopentadecanone were determined by GC analyses on a Hewlett Packard 6890 chromatograph equipped with a flame ionisation detector (FID) using a Hydrodex- $\beta$-3P column $(25 \mathrm{~m}$ x $0.25 \mathrm{~mm}$, [Heptakis(2,6-di- $O$-methyl-3-Opentyl)]- $\beta$-cyclodextrin) and nitrogen as carrier gas. Enantiomeric excesses of the other optically active products were determined by HPLC analyses on JASCO PU-1580 intelligent HPLC pump, equipped with a Varian 2550 UV detector, using a Chiralcel OJ or OD column.

All air- or moisture-sensitive reactions were carried out in flame-dried glassware under a dry nitrogen or argon atmosphere. THF and toluene were refluxed over sodium-benzophenone and distilled before use under nitrogen atmosphere. Triethylamine was refluxed over $\mathrm{CaH}_{2}$ and distilled before use under nitrogen atmosphere. $(R)$ - and $(S)$-BINOL were heated up to $50^{\circ} \mathrm{C}$ under reduced pressure for $4 \mathrm{~h}$ before their use. (S)-2,2'-bis(bromomethyl)-1,1'-binaphthalene 4 was prepared from enantiopure $(S)$-BINOL following a reported procedure. ${ }^{9}$ Unless otherwise specified the reagents were used without any purification.

(S)-(+)-3,5-Dihydro-4H-dinaphth[2,1-c:1'2'-e]azepine- $N$-hydroxide (4). To a solution of triethylamine $(35 \mathrm{ml})$ and hydroxylamine hydrochloride $(1.9 \mathrm{~g}, 27.6 \mathrm{mmol})$, under a nitrogen atmosphere, (S)-2,2'-bis(bromomethyl)-1,1'-binaphthalene 4 (4.05 g, $9.2 \mathrm{mmol}$ ) was added and 
the mixture was warmed up to reflux for $15 \mathrm{~h}$. The precipitate was filtered under reduced pressure and washed with petroleum ether. The product $(1.87 \mathrm{~g}, 65 \%)$ was used without any purification. ${ }^{1} \mathrm{H}-\mathrm{NMR}\left(500 \mathrm{MHz}, \mathrm{CDCl}_{3}\right): \delta(\mathrm{ppm}) 2.80(\mathrm{bs}, 1 \mathrm{H}) ; 3.38(\mathrm{~d}, 1 \mathrm{H}, \mathrm{J}=8.8 \mathrm{~Hz}) ; 3.88$ $(\mathrm{d}, 1 \mathrm{H}, \mathrm{J}=14.3 \mathrm{~Hz}) ; 4.08(\mathrm{~d}, 1 \mathrm{H}, \mathrm{J}=14.3 \mathrm{~Hz}) ; 4.19(\mathrm{~d}, 1 \mathrm{H}, \mathrm{J}=8.8 \mathrm{~Hz}) ; 7.90$ (d, 2H, J = 7.5 Hz); $7.48\left(\mathrm{dd}, 4 \mathrm{H}, \mathrm{J}_{1}=8.0 \mathrm{~Hz} ; \mathrm{J}_{2}=7.5 \mathrm{~Hz}\right) ; 7.63(\mathrm{~d}, 2 \mathrm{H}, \mathrm{J}=8.0 \mathrm{~Hz}) ; 7.96(\mathrm{~m}, 4 \mathrm{H}) ;{ }^{13} \mathrm{C}$ NMR $(125$ $\left.\mathrm{MHz}, \mathrm{CDCl}_{3}\right): \delta(\mathrm{ppm}) 105.0 ; 126.2 ; 126.6 ; 127.7 ; 127.8 ; 128.6 ; 128.8 ; 133.6 ; 133.8 ; 143.4 ;$ 159.9 .

(S)-(+)-3,5-Dihydro-4H-dinaphth[2,1-c:1'2'-e]azepine (3). $N$-Hydroxy-azepine 4 (1.87 g, 5.96 mmol) was added to 2:1 solution of EtOH: satd. $\mathrm{NH}_{4} \mathrm{Cl}$. Indium powder (34 $\left.\mathrm{mg}, 3 \mathrm{mmol}\right)$ and zinc $(0.78 \mathrm{~g}, 12 \mathrm{mmol})$ were than added and the mixture was stirred and refluxed for $27 \mathrm{~h}$. After cooling, the mixture was filtered on Celite and concentrated. A satd. $\mathrm{Na}_{2} \mathrm{CO}_{3}$ solution was added and the solution was extracted with ethyl acetate. The organic phase was dried over anhydrous $\mathrm{Na}_{2} \mathrm{SO}_{4}$ and the solvent evaporated in vacuo. The crude product was purified on silica gel (diethyl ether/methanol 9/1) affording binaphthylazepine 3 as white solid (1.71 g, 97\%). M.p. $147-149^{\circ} \mathrm{C} ;[\alpha]_{D}^{25}=+543.7\left(0.54, \mathrm{CHCl}_{3}\right)$ (Lit. $\left.[\alpha]_{D}^{25}=+574.8\left(0.7, \mathrm{CHCl}_{3}\right)^{13}\right) ;{ }^{1} \mathrm{H}-\mathrm{NMR}(500$ $\left.\mathrm{MHz}, \mathrm{CDCl}_{3}\right): \delta(\mathrm{ppm}) 2.12(\mathrm{bs}, 1 \mathrm{H}) ; 3.53(\mathrm{~d}, 2 \mathrm{H}, \mathrm{J}=11.7 \mathrm{~Hz}), 3.85(\mathrm{~d}, 2 \mathrm{H}, \mathrm{J}=11.7 \mathrm{~Hz})$; 7.23$7.31(\mathrm{~m}, 2 \mathrm{H}) ; 7.43-7.50(\mathrm{~m}, 4 \mathrm{H}) ; 7.58(\mathrm{~d}, 2 \mathrm{H}, \mathrm{J}=8.3 \mathrm{~Hz}) ; 7.94-8.02(\mathrm{~m}, 4 \mathrm{H}) ;{ }^{13} \mathrm{C} \mathrm{NMR}(125$ $\left.\mathrm{MHz}, \mathrm{CDCl}_{3}\right): \delta(\mathrm{ppm}) 48.4 ; 125.2 ; 125.6 ; 126.8 ; 127.1 ; 128.1 ; 128.7 ; 131.2 ; 132.8 ; 134.6$; 134.8 .

\section{$O, O$ '-(R)-(1,1'-dinaphthyl-2,2'-diyl)- $N$-(S)-2-[2,2'-(2-azapropane-1,3-diyl)-1,1'-binaphthyl]}

phosphoramidite $(\boldsymbol{R}, \boldsymbol{S})-\mathbf{1}$. To a stirred solution of azepine $3(0.272 \mathrm{~g}, 0.92 \mathrm{mmol})$ and $\mathrm{Et}_{3} \mathrm{~N}$ $(0.80 \mathrm{ml}, 5.72 \mathrm{mmol})$ in dry THF $(6 \mathrm{ml})$ freshly distilled $\mathrm{PCl}_{3}(0.10 \mathrm{ml}, 1.14 \mathrm{mmol})$ was added, at $0^{\circ} \mathrm{C}$ and under nitrogen atmosphere. The mixture was warmed to room temperature and stirred for $2 \mathrm{~h}$. After cooling to $0^{\circ} \mathrm{C}$, enantiopure $(R)$-BINOL was added and the mixture was stirred at room temperature for $19 \mathrm{~h}$. The resulting mixture was diluited with toluene and filtered on neutral aluminium oxide. The solution was concentrated at reduced pressure and the product was purified by flash chromatography on neutral aluminum oxide (petroleum ether/dichloromethane 6/4) obtaining $220 \mathrm{mg}(40 \%)$ of pure phosphoramidite as a white solid. M.p. $197-200^{\circ} \mathrm{C} ;[\alpha]_{D}=$ -119.4 (0.55, $\left.\mathrm{CH}_{2} \mathrm{Cl}_{2}\right) ;{ }^{1} \mathrm{H}-\mathrm{NMR}\left(500 \mathrm{MHz}, \mathrm{CDCl}_{3}\right)$ : $\delta(\mathrm{ppm}) 3.67\left(\mathrm{dd}, 2 \mathrm{H}, \mathrm{J}_{1}=12.7 \mathrm{~Hz}, \mathrm{~J}_{2}=5.7\right.$ $\mathrm{Hz}) ; 4.20\left(\mathrm{dd}, 2 \mathrm{H}, \mathrm{J}_{1}=12.7 \mathrm{~Hz}, \mathrm{~J}_{2}=7.7 \mathrm{~Hz}\right) ; 7.23-7.32(\mathrm{~m}, 4 \mathrm{H}) ; 7.34-7.43(\mathrm{~m}, 6 \mathrm{H}) ; 7.46-7.56$ $(\mathrm{m}, 6 \mathrm{H}) ; 7.95-8.03(\mathrm{~m}, 6 \mathrm{H}) ; 8.12(\mathrm{~d}, 1 \mathrm{H}, \mathrm{J}=8.0 \mathrm{~Hz}) ; 8.22(\mathrm{~d}, 1 \mathrm{H}, \mathrm{J}=8.5 \mathrm{~Hz}) ;{ }^{13} \mathrm{C}-\mathrm{NMR}(125$ $\left.\mathrm{MHz}_{\mathrm{CDCl}}\right): \delta(\mathrm{ppm}) 48.6 ; 48.7 ; 122.2 ; 122.3 ; 123.1 ; 123.2 ; 125.1 ; 125.2 ; 125.9 ; 126.0 ; 126.1$; $126.5 ; 127.4 ; 127.5 ; 127.6 ; 127.7 ; 128.5 ; 128.6 ; 128.7 ; 129.2 ; 129.3 ; 130.3 ; 130.6 ; 130.7 ; 131.2 ;$ $131.6 ; 133.1 ; 133.2 ; 133.4 ; 133.5 ; 135.3 ; 149.8 ; 150.0$. Anal. Calcd. for $\mathrm{C}_{42} \mathrm{H}_{28} \mathrm{NO}_{2} \mathrm{P}: \mathrm{C}, 82.74$; H, 4.63; N, 2.30. Found: C, 82.71; H, 4.61; N, 2.31 .

$O, O$ '-(S)-(1,1'-dinaphthyl-2,2'-diyl)- $N$-(S)-2-[2,2'-(2-azapropane-1,3-diyl)-1,1'-binaphthyl] phosphoramidite $(\boldsymbol{S}, \boldsymbol{S})-\mathbf{2}$. It was prepared $(40 \%$ yield) following the same synthetic procedure used for $(R, S)-1$. M.p. $191-194^{\circ} \mathrm{C} ;[\alpha]_{D}=+195.4\left(0.65, \mathrm{CH}_{2} \mathrm{Cl}_{2}\right) ;{ }^{1} \mathrm{H}-\mathrm{NMR}\left(500 \mathrm{MHz}, \mathrm{CDCl}_{3}\right)$ : $\delta(\mathrm{ppm}) 3.63\left(\mathrm{dd}, 2 \mathrm{H}, \mathrm{J}_{1}=13.2 \mathrm{~Hz}, \mathrm{~J}_{2}=5.2 \mathrm{~Hz}\right) ; 4.17\left(\mathrm{dd}, 2 \mathrm{H}, \mathrm{J}_{1}=13.2 \mathrm{~Hz}, \mathrm{~J}_{2}=8.2 \mathrm{~Hz}\right) ; 7.24-$ 7.28 (m, 4H); 7.32-7.40 (m, 6H); 7.45-7.53 (m, 6H); 7.93-8.01 (m, 6H); 8.10 (d, 1H, J = 8.2 Hz); 
$8.19(\mathrm{~d}, 1 \mathrm{H}, \mathrm{J}=8.2 \mathrm{~Hz}) ;{ }^{13} \mathrm{C}-\mathrm{NMR}\left(125 \mathrm{MHz}, \mathrm{CDCl}_{3}\right): \delta(\mathrm{ppm}) 48.5 ; 48.7 ; 122.2 ; 123.1 ; 125.1$; $125.9 ; 126.1 ; 126.4 ; 126.5 ; 127.3 ; 127.4 ; 127.5 ; 127.7 ; 128.5 ; 128.6 ; 129.3 ; 130.2 ; 130.6 ; 131.4$; $131.6 ; 133.1 ; 133.4 ; 133.5 ; 135.3 ; 150.0$. Anal. Calcd. for $\mathrm{C}_{42} \mathrm{H}_{28} \mathrm{NO}_{2} \mathrm{P}: \mathrm{C}, 82.74 ; \mathrm{H}, 4.63 ; \mathrm{N}$, 2.30. Found: C, 82.78; H, 4.65; N, 2.31 .

\section{General procedure for the conjugate addition of dialkylzinc reagents to enones}

A solution of $\mathrm{Cu}(\mathrm{OTf})_{2}(5 \mathrm{mg}, 0.014 \mathrm{mmol})$ and chiral ligand $(0.030 \mathrm{mmol})$ in toluene $(4 \mathrm{ml})$ was stirred for $1 \mathrm{~h}$ at room temperature under a nitrogen atmosphere. To this catalyst solution enone (0.5 mmol) was added and, after cooling to the reported temperature (see Tables 1, 2, 3), diethylzinc (1.0 $\mathrm{M}$ in hexane, 1.5 equiv.) [or dimethylzinc (2.0 $\mathrm{M}$ in toluene, 2.0 equiv.)] was added dropwise. The mixture was stirred and monitored by TLC and GC-MS analyses. After complete conversion, the reaction mixture was poured into $10 \mathrm{ml}$ of $1.0 \mathrm{M} \mathrm{HCl}$ solution and extracted three times with diethyl ether. The combined organic phases were washed with brine, dried on anhydrous sodium sulfate and the solvent was evaporated in vacuo. The crude products were purified by column chromatography $\left(\mathrm{SiO}_{2}\right.$, petroleum ether/ diethyl ether).

For the purification of 3-ethylcyclohexanone, due to volatility of this compound, a different procedure was used: the reaction mixture was poured in $10 \mathrm{ml}$ of $1.0 \mathrm{M} \mathrm{HCl}$ solution and extracted three times with diethyl ether; the organic phases were washed with brine, dried on anhydrous sodium sulfate and filtered. Diethyl ether was removed under controlled pressure (700-500 mbar) at room temperature, affording the crude product in toluene which was isolated by flash column chromatography $\left(\mathrm{SiO}_{2}\right.$, pentane/ diethyl ether 5/ 1) as a colorless liquid.

\section{Acknowledgements}

Financial support from MIUR-COFIN 2004 "Aromi e fragranze" and Università degli Studi della Basilicata is gratefully acknowledged.

\section{References and Notes}

1. (a) Alexakis, A.; Benhaim, C. Eur. J. Org. Chem. 2002, 3221. (b) Krause, N; HoffmanRöder, A. Synthesis 2001, 171. (c) Feringa, B. L. Acc. Chem. Res. 2000, 33, 346.

2. (a) Alexakis, A.; Benhaim, C.; Fournioux, X.; Van den Heuvel, A.; Leveque, J.-M.; March, S.; Rosset, S. Synlett 1999, 1811. (b) Naasz, R.; Arnold, L. A.; Pineschi, M.; Keller, E.; Feringa, B. L. J. Am. Chem. Soc. 1999, 121, 1104. (c) Arnold, L. A.; Naasz, R.; Minnaard, A. J.; Feringa, B. L. J. Am. Chem. Soc. 2001, 123, 5841. (d) Degrado, S. J.; Mizutani, H.; Hoveyda, A. H. J. Am. Chem. Soc. 2001, 123, 755. (e) Alexakis, A.; March, S. J. Org. Chem, 2002, 67, 8753. (f) Cesati, R. R.; de Armas, J.; Hoveyda, A. H. J. Am. Chem. Soc. 2004, 126, 96. (g) Dijk, E. W.; Panella, L.; Pinho, P.; Naasz, R.; Meetsma, A.; Minnaard, A. 
J.; Feringa, B. L. Tetrahedron 2004, 60, 9687. (h) Scafato, P.; Cunsolo, G.; Labano, S.; Rosini, C. Tetrahedron 2004, 60, 8801. (i) Scafato, P.; Larocca, A.; Rosini, C. Tetrahedron: Asymmetry 2006, 17, 2511.

3. (a) Alexakis, A.; Mutti, S.; Normant, J. F. J. Am. Chem. Soc. 1991, 113, 6332. (b) Alexakis, A.; Frutos, J.; Mangeney, P. Tetrahedron: Asymmetry 1993, 4, 2427.

4. (a) De Vries, A. H. M.; Meetsma, A.; Feringa, B.L. Angew. Chem. Int. Ed. 1996, 35, 2374. (b) Feringa, B. L.; Pineschi, M.; Arnold, L. A.; Imbos, R; De Vries, A. H. M. Angew. Chem. Int. Ed. 1997, 36, 2620. (c) Arnold, L. A.; Imbos, R; Mandoli, A.; De Vries, A. H. M.; Naasz, R.; Feringa, B. L. Tetrahedron 2000, 56, 2865.

5. (a) Alexakis, A.; Polet, D.; Rosset, S.; March, S. J. Org. Chem, 2004, 69, 5660. (b) Alexakis, A.; Benhaim, C.; Rosset, S.; Humam, M. J. Am. Chem. Soc. 2002, 124, 5262. (c) Alexakis, A.; Rosset, S.; Allamand, J.; March, S. ; Guillen, F.; Benhaim, C. Synlett, 2001, 1375.

6. For recent applications see: (a) Ooi, T.; Takada, S.; Doda, K.; Maruoka, K. Angew. Chem. Int. Ed. 2006, 45, 7768; Angew. Chem. Int. Ed. 2006, 45, 7606. (b) Vachon, J.; Lauper, C.; Ditrich, K.; Lacour, J. Tetrahedron: Asymmetry 2006, 17, 2334. (c) Kano, T.; Yamaguchi, Y.; Tokuda, O.; Maruoka, K. J. Am. Chem. Soc. 2005, 127, 16408. (d) Kano, T.; Takai, T.; Tokuda, O.; Maruoka, K. Angew. Chem. Int. Ed. 2005, 44, 3055. (e) Ooi, T.; Uematsu, Y.; Kameda, M.; Maruoka, K. Angew. Chem. Int. Ed. 2002, 41, 1551.

7. For recent applications see: (a) Arai, T.; Watanabe, M.; Yanagisawa, A. Org. Lett. 2007, 9, 3595. (b) Drommi, D.; Saporita, M.; Bruno, G.; Faraone F.; Scafato, P.; Rosini, C. Dalton Trans. 2007, 1509. (c) Arai, T.; Watanabe, M.; Fujiwara, A.; Yokoyama, N.; Yanagisawa, A. Angew. Chem. Int. Ed. 2006, 45, 5978. (d) Superchi, S.; Giorgio, E.; Scafato, P.; Rosini, C. Tetrahedron: Asymmetry 2002, 13, 1385. (e) Widhalm, M.; Nettekoven, U.; Mereiter, K. Tetrahedron: Asymmetry 1999, 10, 4369.

8. Mecca, T.; Superchi, S.; Giorgio, E.; Rosini, C. Tetrahedron: Asymmetry 2001, 12, 1225.

9. Cicchi, S.; Bonanni, M.; Cardona, F.; Revuelta, J.; Goti, A. Org. Lett. 2003, 5, 1773.

10. (a) Escher, I. H.; Pfaltz, A. Tetrahedron 2000, 56, 2879. (b) Knobel, A. K. H.; Escher, I. H.; Pfaltz, A. Synlett 1997, 1429.

11. (a) Brenna, E.; Fuganti, C.; Serra, S. Tetrahedron: Asymmetry 2003, 14, 1. (b) Fujimoto, S.; Yoshikawa, K.; Itoh, M.; Kitahara, T. Biosci. Biotechnol. Biochem. 2002, 66, 1389. (c) Kraft, V. P.; Bajgrowitz, J. A.; Denis, C.; Frater, G. Angew.Chem. Int. Ed. Eng. 2000, 39, 2980. (d) Kamat, V. P.; Hagiwara, H.; Katsumi, T.; Hoshi, T.; Suzuki, T; Ando, M. Tetrahedron 2000, 56, 4397. (e) Oppolzer, W.; Radinov, R. N. J. Am. Chem. Soc. 1993, 115, 1593. (f) Tanaka, K.; Matsui, J.; Suzuki, H. J. Chem. Soc. Perkin Trans. 1, 1993, 153. (g) Branca, Q.; Frischli, A. Helv. Chim. Acta 1977, 95, 925.

12. (a) Woodward, S. Chem. Eur. J. 2003, 9, 776. (b) Scafato, P.; Labano, S.; Cunsolo, G.; Rosini, C. Tetrahedron: Asymmetry 2003, 14, 3873. (c) Choi, Y. H.; Choi, J. Y.; Yang, H. Y.; Kim, Y. H. Tetrahedron: Asymmetry 2002, 13, 801.

13. Hawkins, J. M.; Lewis T. A. J. Org. Chem. 1992, 57, 2114. 